It seemed appropriate to look at One Hundred

OPINION

Years Ago again, publishing 'snatches' of

content from the BDJ at the start of the 20 th

century.

\title{
Nothing changes ... or does it?
}

In the 1980s and early 90 s the $B D J$ published an occasional 'filler' in the white space at the end of a paper called One Hundred Years Ago. As the title suggests this was a short extract from an issue of the $B D J$ of approximately 100 years ago, reporting on dental news items and often revealing the thinking of that time. The content of these extracts included stories of dentists remonstrating with patients over the non-payment of dentures or describing a unique clinical situation, not unlike some of the letters we publish today. I always appreciated this filler, liked the idea and enjoyed reading about life at the turn of the (then nineteenth) century.

The $B D J$ continued to publish this filler until February 1994, then for reasons lost in the mists of time One Hundred Years Ago ceased. Time moved on, and the arrival of a new editorial assistant in the $B D J$ office stimulated a reappraisal of the various fillers we publish to 'fill' the space when a paper does not finish at the end of the page. It seemed appropriate to look at One Hundred Years Ago again, publishing 'snatches' of content from the $B D J$ at the start of the 20th century. The first of these new fillers appeared in 9th August issue (BDJ 2003; 195: 127) and featured quotes from the AGM of the BDA in June 1903 in Brighton.

It is fascinating to read what people were saying so long ago, and to ponder on whether we now believe they were wrong or appreciate how they have been proved right. Most would agree with the quote by George Morgan, Senior Surgeon, Royal Alexandria Hospital for Children, in placing the worth and perception of the dentist so neatly. Similarily, the frustration of the BDA President concerning the dentists who only wish to take from society (in this case the dentists who cannot see the point of joining the BDA unless they get a direct and immediate return) doubtless raises a wry smile today. It appears nothing changes.

Or does it? If you read the $B D J s$ of 100 years ago more thoroughly you will discover that there are definite differences between then and now, as well as the similarities. For example the profession was very vexed with the problem of the illegal practice of dentistry and the Letters Page contains reports of such occurrences. When a person was discovered to be practising dentistry illegally then a local dentist would write in with the name of the perpetrator in the hopes others would confirm the illegal practice and something could be done. Out of interest this practice did not always produce the hoped-for result, as one such exchange of letters published in the $B D J$ demonstrates. Unlike today, the full exchange of letters between the Hon. Secretary of the Association and an aggrieved member (BDJ 1902; 23: 55-58) concerning the illegal practice of an individual was reproduced in full. The member felt aggrieved at the stance taken by the Association and asked for all the correspondence to be published - which it was. To my mind the saga illustrates the reasonable approach taken by the Secretary and the unreasonable expectations of the member, but you might well expect me to say that. It would be interesting to see if some of the correspondents who write to complain to the BDA would like their letters published in such a fashion today.

Following on from this, the April 15th issue (1902) (BDJ 2003; 195: 241) also reproduces some interesting correspondence, but this time from a hospital in the United States which (on payment of the joining fee) entitles the dentist to a spectacular bunch of benefits. These include a lithograph pocket Membership Ticket, a Red Cross solid gold button, a 25\% cash commission paid for any patients sent to the hospital, free consultation on difficult cases and the promise of writing to 12 names in your locality recommending you to each one (including the local newspaper). This is described as 'instructive reading' demonstrating the slightly dubious ethics of such practice. Perhaps the $B D J$ should do the same today for letters received from certain individuals and groups, except that they are usually less blatant in their correspondence (and also potentially more likely to sue).

Delving into the history of our profession via the pages of the $B D J$ is fascinating, enlightening, amusing and instructive. The problem is - it can be hard deciding if nothing really changes after all and then realising it does, or believing that things continue to change and then discovering they don't.

Mike Grace, Editor

m.grace@bda.org

doi:10.1038/sj.bdj.4810590 